\title{
Risk Indicators of Diabetic Retinopathy in Patients with type 2 Diabetes Screened by Fundus Photographs: A Study from Rural India
}

\author{
B. Silpa ${ }^{1}$, Srikanth Evuru ${ }^{2}$ \\ ${ }^{1}$ Fellow in Medical Retina, Sankara hospital, Guntur. \\ ${ }^{2}$ Cosultant physician and Diabetologist, Mamatha hospital, Tenali, Guntur district, AP, India
}

\begin{abstract}
This study aims to evaluate the risk indicators of diabetic retinopathy in patients with type 2 diabetes screened by fundus photographs at a tertiary care diabetes centre in Tenali, AP, INDIA. A cross-sectional study was conducted at the outpatient department of MAMATHA HOSPITAL, TENALI, from October 2015 to March 2016. Patients $\geq 30$ years of age were recruited randomly. Demographic, anthropometric, clinical and biochemical data were collected, and ophthalmic screening was done by two field fundus photography. Fundus photographs of 366 patients were graded according to the modified Early Treatment Diabetic Retinopathy Disease Severity Scale (ETDRS) criteria. Retinopathy was present in $27.3 \%$ patients. Fifteen percent of patients had non-sight-threatening retinopathy while $12 \%$ had sight-threatening retinopathy. Patients with retinopathy had significantly increased mean duration of diabetes, systolic and diastolic blood pressure and HbAlc(p<0.001). patients with sight-threatening retinopathy also had increased serum cholesterol $(p<0.05)$ and serum creatinine $(p<0.001)$. Multivariate logistic regression revealed male gender $(3.5$ times, $95 \%$ confidence interval (CI); 1.73-7.12), increased duration of diabetes ( $\geq 10$ years, 5.46 times, 95\% CI; 2.15-13.85), hypertension ( $\geq 130 / 85$, 1.96 times, $95 \% \mathrm{CI} ; 0.95$ - 4.03) and poor glycemic control (HbAlc $\geq 7 \%$, 1.39 times, CI; 1.23 - 1.56) as significant factors for developing retinopathy. Diabetic retinopathy was present in every fourth subject, while sight-threatening retionopathy was present in every eighth subject with type 2 diabetes. The results of the present study highlight the importance of screening for retinopathy. The identification of risk indicators associated with retinopathy in our population may lead to measures of prevention of sight-threatening complication of diabetes. Fundus photographs revealed increased frequency of retinopathy among patients with type II diabetes. Male gender, increased mean duration of diabetes, hypertension and poor glycemic control related with the presence of retinopathy, while increased serum cholesterol and creatinine related with severity of retinopathy. The present study highlights the importance of screening for retinopathy. The presence and severity of retinopathy in this population was attributed to the factors identified in earlier studies. The present study thus validated the findings of studies conducted on diverse populations across the world.
\end{abstract}

Keywords: Retinopathy. Fundus photography. Risk indicators. Diabetes

\section{Introduction}

Diabetes mellitus is considered as one of the leading causes of kidney failure, non-traumatic lower limb amputations and new cases of blindness in the developed world [1]. This over whelming morbidity of diabetes in largely attributed to longterm chronic complication [2]. Diabetic retinopathy (DR) is one of the microvascular complications of diabetes and a leading cause of visual disability and acquired blindness [3]. Visual impairment as a result of diabetic retinopathy not only has significant impact on quality of life but it can also compromise the ability of a patient to manage his disease successfully [4]. It is also found to have an impact on the incidence of other diabetic complications and overall life expectancy [5].

With increasing prevalence of diabetes, global data support the assumption that DR will become one of the most important causes of blindness in the future. It is anticipated that $20 \%$ of people with diabetes will develop DR [6-9]. This alarming situation prompted the investigators to focus on the tertiary prevention of diabetes. A series of epidemiological studies on DR were initiated and identified several factors related with the development and progression of this complication [10 - 16]. However, due to ethnic disparity, difference in life styles and food habits, distinct environment and diverse genetic susceptibility, their findings need to be validated in our population.
Since exploration of the factors related with DR is necessary for the prevention and management of this diabetes complication, some investigators have attempted to address this issue in Pakistan [17 - 23]. However, as far as the literature search done, this is the first study in which screening for DR was carried out by fundus photography, a more sensitive and specific method for the screening of retinopathy than ophthalmoscope [24]. Thus, based on the findings of fundus photographs, two distinct cohorts of diabetic patients with retinopathy and without retinopathy were assembled with reliability. Hence, the present study was designed to find out the association of various factors with retinopathy.

\section{Methods}

This cross-sectional study was conducted at MAMATHA HOSPITAL, TENALI, from October 2015 to March 2016. Patients were recruited randomly from the outpatient department of MHT after taking a signed informed consent. Greater than 30 - year - old patients with type 2 diabetes of either sex were considered eligible to participate in the study. Patients with type 1 diabetes and pregnant women were excluded. Data on demographic, anthropometric, clinical and biochemical parameters was collected for each recruited patient. 


\section{International Journal of Science and Research (IJSR) \\ ISSN (Online): 2319-7064}

Index Copernicus Value (2013): 6.14 | Impact Factor (2015): 6.391

\section{Anthropometry}

Height and weight of participants were measured in light clothes after their consent. A digital scale placed on a flat surface was used for measurement of weight. Weight was recorded to the nearest $0.1 \mathrm{~kg}$. Height was measured in erect posture, touching the occiput, back, hip and heels on the wall. Height was taken to the nearest of $0.1 \mathrm{~cm}$. body mass index (BMI) was calculated as weight in kilograms per height in square metres. Blood pressure was measured by adult-fitted standard cuffs in sitting position after $10 \mathrm{~min}$ of rest. Hypertension was defined as a blood pressure of $\geq$ 130/85 mmHg [25]. Hypertensive also included subjects with known hypertension who were already on antihypertensive medications prescribed by a doctor.

\section{Ophthalmic examination}

Each recruited patient went through ophthalmic examination by fundus camera (Canon CR - I) for screening of diabetic retinopathy. After checking the best corrected visual acuity by internally illuminated Snellen's chart, one to two drops of phenylephrine was instilled in both eyes of the patients. After 20 - 30 min when the pupils were dilated, two field fundus photographs of each eye were taken, one central to the optic disc and the other central to macula. All retinal photographs were graded by a retinal specialist according to the Diabetic Retinopathy Disease Severity Scale, a modification of the Early Treatment Diabetic Retinopathy Disease Severity Scale (ETDRS) [26].

Based on the findings of fundus photographs, patients with signs of diabetic retinopathy were categorized into the DR group and those without sign of retinopathy were in the NDR group. Patients with retinopathy (DR group) were subsequently sub-grouped on the basis of severity of lesions into non-sight-threatening diabetic retinopathy (NSTDR) and sight-threatening diabetic retinopathy (STDR) groups. Since mild or moderate non-proliferative diabetic retinopathy (NPDR) does not pose immediate threat to vision, they were collectively labelled as NSTDR. Diabetic retinopathy that needs immediate referral and urgent treatment was categorized as STDR. PDR and diabetic macular edema alone or in combination with NPDR or PDR were included in the category of STDR.

It is not necessary that both eyes of a person be affected simultaneously and if affected, to be affected by the same severity. Therefore, the presence of retinopathy signs in any eye was considered as sufficient evidence to categorize a person as having diabetic retinopathy. Similarly, the presence of sign of retinopathy of lower grading scale in one eye while higher grading scale in the other eye renders the patient in the

\section{Laboratory assays}

Within an hour of blood collection, the samples were centrifuged and separated. Fasting, 2-h blood glucose and lipid profile 9serum cholesterol, triglyceride, serum high density lipo-protein) were analyzed by enzymatic colorimetric methods. All these measurements were done by an automatic analyzer (Hitachi 704, Hitachi Ltd Tokyo, Japan) using reagents of Randox Laboratories Ltd. LDL-c was estimated by using standard formula.

\section{Statistical analysis}

To explore the influence of various factors on development of retinopathy, succession of univariate was done initially by applying chi square and independent sample $t$ test for categorical and continuous variable, respectively. A $p<0.05$ was considered statistically significant.

Variables with significant difference in univariate analysis were then entered in the logistic model and categorized into two levels $(\mathrm{R}=$ reference category): sex $=$ female $(\mathrm{R})$, male; duration of diabetes (years) $=\leq 10(\mathrm{R}), \geq 10$; glycemic state $=$ HbAlc $\leq 7 \%(\mathrm{R}), \geq 7 \%$ and hypertension $=\leq 130 / 85(\mathrm{R})$, $\geq 130 / 85$. The outcome of logistic regression analysis was expressed in terms of odds ratios (OR) along with their $95 \%$ confidence intervals $(95 \% \mathrm{CI})$. All analysis was performed by using SPSS version 13.0.

\section{Results}

Out of 366 patients, $137(37.4 \%)$ were males. Mean ( \pm SD) age of the study patients was $48.08 \pm 8.02$ years, duration of diabetes was $9.17 \pm 6.51$ (years) and BMI was $28.6 \pm 5.16$ $\left(\mathrm{kg} / \mathrm{m}^{2}\right)$. Retinopathy was evident in the fundus photographs of $27.3 \%(n=100)$ patients. Fifteen percent had non-sightthreatening (NSTDR) while $12.3 \%$ had sight-threatening diabetic retinopathy (STDR) (Fig. 1).

Patients with retinopathy (both non-sight threatening and sight threatening) had significantly increased mean duration of diabetes, systolic and diastolic blood pressure and HbAlc than patients without retinopathy (NDR) $(\mathrm{p}<0.001)$. however, patients with sight-threatening retinopathy also had significantly increased serum cholesterol $(\mathrm{p}<0.05)$ and serum creatinine $(\mathrm{p}<0.001)$ than the NDR group (Table 1$)$.

Multivariate logistic regression analysis revealed gender as a significant factor; with male carrying 3.5 times $(95 \% \mathrm{CI}$; 1.73 - 7. 12) more risk for developing retinopathy. A diabetic patient with $\geq 10$ years of disease history is 5.46 times $(95 \% \mathrm{CI} ; 2.15-13.85)$ at risk to have retinopathy than those with $\leq 10$ years of diabetes. Hypertensive patients develop retinopathy twice as often as normotensive patients (1.96 times, CI; 0.95 - 4.03). while patients with poor glycemic control (HbAlc $\geq 7 \%$ ), were 1.39 times $(95 \% \mathrm{CI}$; 1.23 - 1.56) more likely to have retinopathy than patients with good glycemic control (Table 2).

\section{Discussion}

Diabetic retinopathy is one of the most common microvascular complications of diabetes with varying reported prevalence [10 - 14]. Even studies originating from Pakistan also corroborate the variable prevalence of retinopathy ranges from 15.7 to $55 \%$ [7, 18, 27, 28]. In the present study, frequency of retinopathy was found to be 27.3 $\%$. These inflections in the reported frequencies of retinopathy could be attributed to inclusion of both patients with type 1 and type 2 diabetes, use of difference definitions of diabetes and diabetic retinopathy as well as use of different screening techniques and grading systems in various studies. Thus, direct comparison of the different frequency of diabetic retinopathy in different populations is difficult. However, the presence of higher frequency of 


\section{International Journal of Science and Research (IJSR) \\ ISSN (Online): 2319-7064}

Index Copernicus Value (2013): 6.14 | Impact Factor (2015): 6.391

retinopathy in the present study warrants mandatory ophthalmic examination and demands patient compliance according to the recommended international guidelines for screening of T2DM patients [29].

Predicting male gender as a risk factor for developing diabetic retinopathy in our study is in accordance with a study done in Chennai, India, that showed diabetic retinopathy was more prevalent in males [30]. A similar male preponderance has been reported in some other studies [8, 31, 32]. In contrast,

Table 1: Comparison of demographic, anthropometric, clinical and biochemical characteristics of non-sightthreatening (NSTDR) and sight-threatening diabetic retinopathy (STDR) with no diabetic retinopathy (NDR)

\begin{tabular}{|l|l|}
\hline Variables & NDR \\
$n$ & 266 \\
\hline Age (years) & $48.69 \pm 8.23$ \\
Male & $85(31.9 \%)$ \\
Female & $181(68.1 \%)$ \\
Duration of diabetes (years) & $7.71 \pm 5.74$ \\
Weight (kg) & $73.28 \pm 14.02$ \\
Height (cm) & $159.93 \pm 8.75$ \\
Body mass index (kg/m $\left.{ }^{2}\right)$ & $28.65 \pm 5.17$ \\
Diastolic blood pressure (mmHg) & $79.29 \pm 10.4$ \\
Systolic blood pressure (mmHg) & $125.32 \pm 17.71$ \\
Fasting blood sugar (mg/d) & $166.63 \pm 56.37$ \\
Random blood sugar (mg/dl) & $200.74 \pm 76.7$ \\
HbAlc (\%) & $8.75 \pm 2.11$ \\
Total cholesterol (mg/dl) & $177.82 \pm 38.87$ \\
Triglyceride (mg/dl) & $179.86 \pm 64.57$ \\
HDL (mg/dl) & $42.20 \pm 8.48$ \\
LDL (mg/d) & $108.71 \pm 27.6$ \\
Serum creatinine (mg/dl) & $0.99+0.29$ \\
\hline
\end{tabular}

Serum creatinine (mg/dl) $0.99+0.291 .05+0.351 .54+0.74 * *$ Values are expressed as mean $\pm \mathrm{SD} / n(\%)$. Student $t$ test/chi square test was used as a test of significance for comparison between without diabetic retinopathy (NDR) with non-sightthreatening diabetic retinopathy (NSTDR) and sightthreatening diabetic retinopathy (STDR) groups

$*<0.05 p$ value was considered statistically significant $* *<0.001 p$ value was considered statistically significant

Other studies have not shown a consistent pattern of gender variation in the prevalence of diabetic retinopathy $[12,15$, 16]. Multivariate logistic regression analysis showed that males are 3.5 times more prone to develop DR. though the exact reason is not known, this gender preponderance may be due to the presence of some confounding factors such as obesity or hypertension. However, further research is needed to elucidate the causes of this variation of diabetic retinopathy frequency in gender. Age is not a risk factor for developing diabetic retinopathy. Like diabetes, DR may develop at any age. However, those
Table 2: Risk indicators of diabetic retinopathy explored by logistic regression analysis

\begin{tabular}{|l|l|l|c|l|}
\hline Variables & $\begin{array}{l}\text { Crude } \\
\text { OR }\end{array}$ & $95 \% \mathrm{CI}$ & $\begin{array}{c}\text { Adjusted } \\
\text { OR }\end{array}$ & $95 \% \mathrm{CI}$ \\
\hline 1. Male & 2.31 & $1.44-3.69$ & 3.51 & $1.73-7.12$ \\
$\begin{array}{l}\text { 2. Duration of } \\
\text { Diabetes }(\geq 10 \text { year) }\end{array}$ & 5.47 & $2.52-11.87$ & 5.46 & $2.15-13.85$ \\
$\begin{array}{l}\text { 3. Hypertension } \\
(\geq 130 / 85 \mathrm{mmHg})\end{array}$ & 2.65 & $1.59-4.44$ & 1.96 & $0.95-4.03$ \\
4. HbAlc $(\%)$ & 1.47 & $1.33-1.63$ & 1.39 & $1.23-1.56$ \\
\hline
\end{tabular}

Adjusted for the variables present in the table $O R$ odds ratio; $\mathrm{Cl}$ confidence interval Who acquire the disease at an earlier age are more likely to develop retinopathy [33]. Epidemiological studies found the duration of diabetes to be a kiskTfactor for devefoplitig retin $\phi$ pathy [27, 34]. In the present data, duration of flabetes has also been found to be

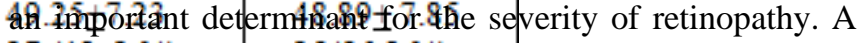

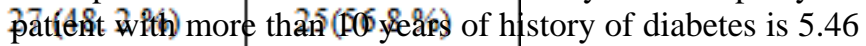

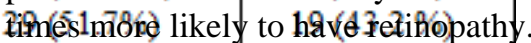
$12.11 \pm 7.16^{* *}$ $14.22 \pm 6.39 * *$

BAMH is leonsidered 160eleppidit of gluc6se1 dysiegulation [35]. However, for devetephaent of diabeti85tefinopathy, contradictory findings

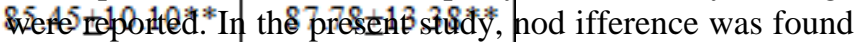

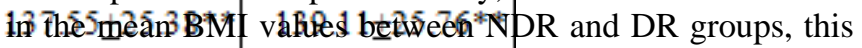

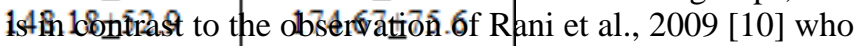

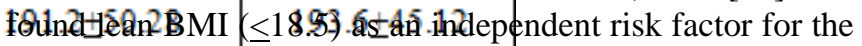

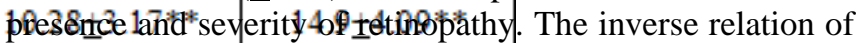

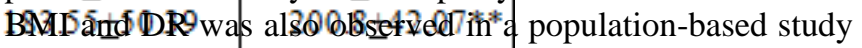
16 1nalia $5109.8 \quad 181.29+69.52$ \begin{tabular}{l|l}
$41.85 \pm 7.18$ & $39.36 \pm 6.13$
\end{tabular}

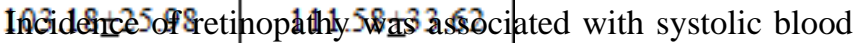
pressture 3 In the United5Kingdêm* Prospective Diabetes Study (UKPDS); while in the Wisconsin Epidemiologic Study of Diabetic Retinopathy (WESDR), diastolic blood pressure was a significant predictor of progression of retinopathy to proliferative diabetic retinopathy over 14 years of follow-up $[36,37]$. In the present study, both systolic and diastolic blood pressure were found to be related with the presence as well as severity of DR in univariate analysis, a finding consistent with the findings of Krishnalal et al., 2007 [11]. Though the exact pathogenesis of hypertension in DR is unknown, hemodynamic alteration in retinal vasculature and hypertension-included increased expression of vascular endothelial growth factors are possible mechanisms involved in DR [38]. In the present study, diabetic subjects with hypertension were found to have twice the risk of developing retinopathy as compared to the normotensive subjects with diabetes.

It is suggested that the development and progression of DR is influenced by the level of hyperglycaemia. A higher HbAlc in both retinopathy groups compared to nonretinopathy group indicates that poor glycemic control plays a role not only in the development but also in the pgoression of retinopathy. Similar findings were observed in the Chennai Urban Rural Epidemiology Study (CURES) and UKPDS [30, 36]. Regression analysis in the present study found that patients with poor glycemic status were 1.39 times more likely to develop diabetic retinopathy. 


\section{International Journal of Science and Research (IJSR) \\ ISSN (Online): 2319-7064}

Index Copernicus Value (2013): 6.14 | Impact Factor (2015): 6.391

Increased total cholesterol in univariate analysis indicated the role of cholesterol in the progression of retinopathy from non-sight threatening to sight-threatening group, a finding consistent with the findings of ETDRS groups [39, 40]. It also conforms to the CURES eye study that found association of retinopathy with total cholesterol [41]. However, multivariate logistic regression analysis in the present study failed to demonstrate any risk-related association of total cholesterol with diabetic retinopathy.

An elevated serum creatinine signifies kidney injury. Increased serum creatinine in patients with sight-threatening retinopathy indicates the coexistence of microvascular complications in both organs. Diabetic retinopathy and nephroathy have been found to be closely related in other epidemiological studies [42, 43].

With limitations of study design and patient selection from a tertiary care diabetes centre that restrict causal relation and external validity, respectively, associations of certain factors with retinopathy in our study, validate the findings of earlier studies. Thus, for decreasing the burden of diabetic retinopathy, it is imperative to control the identified factors, particularly those that are considered avoidable.

\section{Conclusions}

The study helped to identify factors likely to be related to a serious diabetic complication. Male gender, long duration of diabetes, control of hypertension and glycaemia are the important risk indicators of diabetic retinopathy in this group of patients. Good control of the risk indicators explored in the present study may lead to the prevention of this vision-threatening complication of diabetes. The study also underlines the need for screening of patients with diabetes as they are more likely to develop retinopathy.

\section{References}

[1] National diabetes statistics, 2011. National diabetes information clearinghouse (NDIC) available at: http://diabetes,

niddk.nih.gov/dm/pubs/statistics/\#Blindness Access on 02/05/2012.

[2] Reusch JEB. Diabetes, microvascular complications and cardiovascular complications: what is about glucose? J Clin Invest. 2003;112;986-88.

[3] Gupta S. Ambade A. Prevalence of diabetic retinopathy and influencing factors amongst type 2 diabetics from central India. Int J Dev Countries. 2004;24:75-8

[4] Brown MM, Brown GC, Sharma S, Shah G. Utility values and diabetic retinopathy. Am J Ophtalmol. 1999;128:324-30.

[5] Williams R, Airey M. Baxter H, Forrester J. KennedyMartin T, Girach A. Epidemiology of diabetic retinopathy and macular oedema: a systemic review. Eye. 2004;18:963-83.

[6] Narendra V, John RK, Raghuram A, Nirmalan PK, Thulasiraj RD. Diabetic retinopathy a month among self reported diabetics in Southern India: a population based assessment. Br J. Ophthalmol. 2002;86:1014-18.

[7] Rema M, Deepa R, Mohan V. Prevalence of retinopathy at diagnosis among type 2 diabetic patients attending a diabetic centre in South India. $\mathrm{Br} \mathrm{J}$ Ophthalmol. 2000;84:1058-60.

[8] Dandona L, Dandona R, Naduvilath TJ, McCarty CA, Rao GN. Population based assessment of diabetic retinopathy in an urban population in southern India. $\mathrm{Br}$ J Ophthalmol. 1999;83:937-40.

[9] Khandekar R, Al Lawatii J. Mohammad AJ, Al Raisi A. Diabetic retinopathy in Oman: a hospital based study. Br J Ophthamol. 2003;87:1061-64.

[10] Rani PK, Raman R, Chandrakantan A, Pal SS, Perumal GM, Sharma T. Risk factor for diabetic retinopathy in self-reported rural population with diabetes. J Postgrad Med. 2009;55:92-6.

[11] Krishnaiah S, Das T, Nirmalan PK, et al. Risk factors for diabetic retinopathy: findings from the Andhra Pradesh Eye Disease Study. Clin Ophtalmol. 2007; 1:475-82.

[12] Varma R, Torres M, Pena F, Klein R, Azen SP, Los Angeles Latino Eye Study Group. Prevalence of diabetic retinopathy in adult Latino. The Los Angeles Latino Eye Study. Ophthalmology. 2004;111:1298-06.

[13] Mitchell P, Smith W, Wang JJ, Attebo K. Prevalence of Diabetic retinopathy in an older community. The Blue Mountains Eye Study. Ophthalmology. 1998;105:40611.

[14] Van Leiden HA, Dekker JM, Moll AC, et al. Risk factors for incident retinopathy in a diabetic and nondiabetic population: Hoom study. Arch Ophthalmol. 2003;121:245-51.

[15] Wong TY, Klein R, Sharret AR, et al. The prevalence and risk factors of retinal microvascular abnormalities in older persons: the cardio-vascular health study. Ophthalmology. 2003;110:658-66.

[16] Kempen JH, O’Colmain BJ, Leske MC, Eye Diseases Prevalence Research Grop, et al. the prevalence of diabeti retinopathy among adults in the United States. Arch Ophthalmol. 2004;122-552-63.

[17] Chaudhary GM. Retinopathy in diabetic patients. Pak J Med Res. 2005;44:82-6.

[18] Wahab S, Mahmood N, Sheikh Z, Kazmi WH. Frequency of retinopathy in newly diagnosed type 2 diabetes patients. J Pak Med Assoc. 2008;58:557-61.

[19] Mahar PS, Awan MZ, Manzar N, Saleh MS. Prevalence of type II diabetes mellitus and diabetic retinopathy: the Gadap Study. JCPSP. 2010;20:528-32.

[20] Siddiqui SJ, Pechuho MA, Shah SA, Shaikh F, Shaikh AQ. Risk factors associated with diabetic retinopathy (a study of 438 cases at CMC Larkana). Med Channel. 2009; $15: 69-70$.

[21] Arbab TM, Hanif S, Iqbal S, Mirza MA. Hypertension as risk factor in diabetic retinopathy in type 2 diabetes. Pak J Ophthalmol. 2008;24 (4):201-04.

[22] Jamal-u-Din, Qureshi MB, Khan AJ, Khan MD, Ahmad K. Prevalence of diabetic retinopathy among individuals screened positive for diabetes in five community-based eye camps in Northern Karachi, Pakistan. J Ayub Med Coll Abbottabad. 2006;18(3):40-3.

[23] Khanzada MA, Narsani AK, Shaikh F, Jatoi MS. Frequency and types of diabetic retinopathy in type II diabetes: a hospital base study. JLUMHS. 2011;10:14346.

[24] Harding SP, Broadbent DM, Neoh C, White MC, Vora J. Sensitivity and specificity of photography and direct

\section{Volume 5 Issue 6, June 2016}




\section{International Journal of Science and Research (IJSR) \\ ISSN (Online): 2319-7064 \\ Index Copernicus Value (2013): 6.14 | Impact Factor (2015): 6.391}

ophthalmoscopy in screening for sight threatening eye disease: the Liverpool diabetic eye study. BMJ. 1995;311:1131-35.

[25] Anoop M. Jasjeet SW, Ravinder MP. An evaluation of candidate definitions of the metabolic syndrome in adult Asian Indians. Diabetes Care. 2005;28:398-03.

[26] Wilkinson CP, Ferris III FL, Klein RE, et al. Proposed international clinical diabetic retinopathy and diabetic macular edema disease severity scales. Ophthalmology. 2003;110:1677-82.

[27] Niazi KM, Akram A, Naz AM, Awan S. Duration of diabetes as a significant factor for retinopathy. Pak J Ophthlmol. 2010;26(4):182-87.

[28] Rahman S, Zia I. Prevalence of microvascular complications among diabetic patients. Pakistan J Med Res. 2004;43(4):163-8.

[29] ADA position statement. Diabetic retinopathy. Diabetes Care. 2002;25:S90-3.

[30] Rema M, Premkumar S, Anitha B, Deepa R, Pradeepa $\mathrm{R}$, Mohan V. Prevalence of diabetic retinopathy in urban India: the Chennai urban rural epidemiology study (CURES) eye study, I. Invest Ophthalmol Vis Sci. 2005;46:2328-33.

[31] Al-Maskari F, El-Sadig M. Prevalence of diabetic retinopathy in the United Arab Emirates: a crosssectional survey. BMC Ophthalmol. 2007:7:11-9

[32] Kohner EM, Aldington SJ, Stration IM, et al. United Kingdom prospective diabetes study 30. Diabetic retinopathy at diagnosis of non-insulin dependent diabetes mellitus and associated risk factors. Arch Ophthalmol. 1998;116:297-03. Facts about diabetic retinopathy. National eye institute, Available at: http://www.nei.nih.gov/health/diabetic/retinopathy.asp. Access on Feb 2012.

[33] Fond Ds, Ferris FL, Aiello LP, Klein R. Diabetes retinopathy. Diabetes Care. 2004;27:2540-52.

[34]D' Adamo E, Caprio S. Type 2 diabetes in youth: epidemiology and pathophysiology. Diabetes Care 2011;34(2):S161-165.

[35] Rema M, Premakumar S. Diabetic retinopathy. An Indian perspective. Indian J Med Res. 2007;125:297-10.

[36] Klein R, Klein BE, Moss SE, Cruickshanks KJ. The Wisconsin epidemiologic study of diabetic retinopathy: XVII. The 14-years incidence and progression of diabetic retinopathy and associated risk factors in type 1 diabetes. Ophthalmology. 1998;105:1801-15.

[37]Lorenzi M. The polyol pathway as a mechanism for diabetic retinopathy: attractive, elusive, and resilient. In Diabetic Retinopathy: in From Pathogenesis to Treatment. In Experimental Diabetes Research. Hindawi Publishing Corporation Experimental Diabetes Research Volume 2007, Article ID 61038, 10 pages doi: 10.1155/2007/61038.

[38] Ferris III FL, Chew KY, Hoogwerf BJ. Serum lipids and diabetic retinopathy. Early treatment diabetic retinopathy study research group. Diabetes Care. 1996;19:1291-3.

[39] Klein BEK, Moss SE, Klein R, Surawicz TS. The Wisconsin epidemiologic study of diabetic retinopathy. XIII: relationship between serum cholesterol to retinopathy and hard exudates. Ophthalmology. 1991;98:1261-5.
[40] Rema M, Srivastava K, Anitha B, Deepa R, Mohan V. Association of serum lipid with diabetic retinopathy in urban South Indians - the Chennai Urban Rural Epidemiology Study (CURES) eye study - 2. Diabet Med. 2006;23:1029-36.

[41] Porta M, Bandello F. Diabetic retinopathy. A clinical update. Diabetologia. 2002;45:1617-34.

[42] Pedro R, Ramon S, Marc B, JuanF, Isabel $M$. Prevalence and relationship between diabetic retinopathy and nephropathy, and its risk factors in the North-East of Spain, a population-based study. Ophthal Epidemio. 2010;17(4):251-65.

\section{Author Profile}

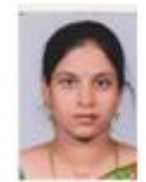

Dr. B.Silpa received MBBS degree from Osmania Medical College, Hyderabad, AP,INDIA, M.S post graduation from Mediciti institute of medical sciences, hyderabad, she worked as senior resident and subsequently working as fellow in medical retina in Sankara Eye Hospital, Chinakakani, Guntur dt.

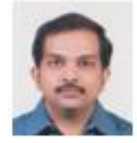

Dr. Srikanth Evuru received MBBS degree from Rangaraya Medical College, Kakinada, AP,INDIA, M.D post graduation from Rajah Muttiah Medical College, Chidambaram, TN, INDIA, he worked as an assistant professor and subsequently working as associate professor at NRI medical college, chinakakani, AP, INDIA 